This page intentionally left blank 


\section{Industrial Buusters}

\section{Biotechnology \\ Driving forces, \\ Development Processes and Management Practices}

\section{Vittorio Chiesa \\ Davide Chiaroni}

Politecnico di Milano, Italy 
Published by

Imperial College Press

57 Shelton Street

Covent Garden

London WC2H 9HE

\section{Distributed by}

World Scientific Publishing Co. Pte. Ltd.

5 Toh Tuck Link, Singapore 596224

USA office: 27 Warren Street, Suite 401-402, Hackensack, NJ 07601

UK office: 57 Shelton Street, Covent Garden, London WC2H 9HE

\section{British Library Cataloguing-in-Publication Data}

A catalogue record for this book is available from the British Library.

\section{INDUSTRIAL CLUSTERS IN BIOTECHNOLOGY \\ Driving Forces, Development Processes and Management Practices}

Copyright $@ 2005$ by Imperial College Press

All rights reserved. This book, or parts thereof, may not be reproduced in any form or by any means, electronic or mechanical, including photocopying, recording or any information storage and retrieval system now known or to be invented, without written permission from the Publisher.

For photocopying of material in this volume, please pay a copying fee through the Copyright Clearance Center, Inc., 222 Rosewood Drive, Danvers, MA 01923, USA. In this case permission to photocopy is not required from the publisher.

ISBN 1-86094-498-1

Typeset by Stallion Press

Email: enquiries@stallionpress.com

Printed in Singapore. 


\section{Preface}

This book collects the main results of the Cleverbio Project. "Cluster development and growth in bio-tech: enabling factors and best practices" (Cleverbio) is a project funded by the European Commission within the Fifth Framework Programme, within the topic "Quality of life and management of living resources". The consortium which carried out the project is composed of six partners: University of Milano-Bicocca (scientific coordinator), Department of Biotechnology and Biosciences, Milano, Italy; Associazione Impresa Politecnico (financial and administrative coordinator), Politecnico di Milano, Milano, Italy; East Region Biotechnology Initiative (ERBI), Cambridge, UK; East Jutland Innovation, Aarhus, Denmark; Heidelberg Technology Park, Heidelberg, Germany; Ecole Superieure d'Ingegnieurs de Marseille, Marseilles, France.

The project studied the cluster development in the biotechnology sector. Clusters can be defined as the geographical concentration of different actors such as interconnected companies, specialised suppliers, service providers, institutions, which compete and cooperate in the same industry. Cluster development is a complex process and usually involves a number of actors such as governmental departments, economic development agencies, public administrations, universities and research centres, companies of different types, financial institutions. 
There is a wide body of literature on clusters. However, most works concentrated on the description of the cluster: who takes part to the cluster, his role, how the interactions take place, which are the main advantages of creating and being part of a cluster. Much less attention has been paid to the dynamics of a biotech cluster: how the cluster developed and develops, which are the key factors enabling the cluster to grow, the main problems faced. The project aimed to give an answer to these questions.

The project objective was to define a normative model for cluster development in the biotech sector, which identifies key mechanisms to favour the growth and development of a cluster and the best practices in use to manage a cluster.

To achieve the above objectives the project has carried out:

- an empirical study on biotech clusters, examining how they work and identifying the critical factors enabling the growth and development of a cluster in the biotech sector;

- a detailed analysis of dynamics, triggers, barriers and problems related to a cluster, in order to capture the best practices and provide key recommendations.

The empirical work consisted of the in-depth analysis of the five clusters represented in the consortium, concerning five different European countries: Denmark, Germany, France, Italy, UK. The clusters examined are at different stages of development:

- Cambridge is the most important cluster in Europe and one of the strongest biotech area at worldwide level,

- Heidelberg is a major European cluster and one of the strongest in Germany,

- Aarhus in Denmark as well as Marseille in France are at an early stage of development,

- Milano in Italy is at an embryonic stage of development.

Moreover, other clusters have been analysed, such as Paris-Evry (France), Uppsala (Sweden), Biovalley (Switzerland), Bay Area and San Diego (US) to have a more comprehensive sample. 
The ultimate result of the project has been to build a normative model for cluster approach in biotech. The normative model identifies the following aspects:

- pre-requisites to cluster approach, i.e. the conditions which allow a cluster to grow;

- driving forces for cluster growth and development, i.e. key mechanisms enabling the cluster to develop;

- best practices in cluster development and management (in relation to barrier removal, solutions to typical problems to be faced etc.).

The book also shows that biotech clusters born and develop on the basis of different processes: some were born and grew spontaneously thanks to the original co-presence of the key success factors (spontaneous clusters) and some others were born as the result of the actions of public actors. Among the latter, this book shows that different mechanisms and policies were at the origin of the process (industry restructuring policies and industry development policies). Finally in few cases the process of clustering started as a result of a combination of different original conditions (hybrid clusters).

This book therefore intends to be of help for: (i) scholars studying the cluster phenomenon and the process of clustering in the biotech (but also, to a larger extent, in high tech industries); (ii) policy makers, involved in the process of undertaking supporting actions to the development of the biotech sector; (iii) managers of institutions, agencies, initiatives in charge of promoting the development of biotech clusters.

The book is composed of ten chapters. The first chapter provides a brief review of the concept of cluster and gives information about the Cleverbio Project. The second chapter gives an overview on the biotech industry (types of firms, business models, sources of competitive advantage). The chapters from three to seven give an overview on the five cluster examined: Cambridge, Heidelberg, Aarhus, Marseille, Milan, whereas the chapter eight describes the main characteristics of other major biotech clusters in the world. Finally, the chapter nine describes the normative model, showing pre-requisites, driving forces and best practices in biotech clusters, and the chapter ten draws some conclusions, identifying the different development processes and clustering forms in the biotech industry. 
On behalf of the consortium, the authors wish to thank the European Commission which made the Cleverbio Project possible and constantly gave its support during the development of the work.

Vittorio Chiesa and Davide Chiaroni Milano, March 2004 


\section{Contributors}

Chapter 3

Jeff Solomon

Chief Executive Officer, East Region Biotechnology Initiative (ERBI), Cambridge, UK.

\section{Claire Skentelbery}

Business Development Manager, East Region Biotechnology Initiative (ERBI), Cambridge, UK.

\section{Chapter 4}

\section{Klaus Plate}

Chief Executive Officer, Heidelberg Technology Park, Heidelberg, Germany.

\section{Marion Kronabel}

Assistant of the Managing Director, Heidelberg Technology Park, Heidelberg, Germany. 


\section{Chapter 5}

\section{Gyda Marie Bay}

Project Manager, East Jutland Innovation A/S, Aarhus, Denmark.

\section{Jørn Enggaard}

Project Manager, East Jutland Innovation A/S, Aarhus, Denmark.

\section{Chapter 6}

\section{Jean Laporta}

Contracting Professor of Engineering, Ecole Supérieure d'Ingénieurs de Marseille (ESIM), Marseilles, France.

\section{Françoise Perrin}

Lecturer in Engineering, Ecole Supérieure d'Ingénieurs de Marseille (ESIM), Marseilles, France. 


\section{Authors}

Vittorio Chiesa is the ENI Professor of R\&D Strategy and Organisation at Politecnico di Milano. He also teaches Business Economics and Organisation at Politecnico di Milano and the University of MilanoBicocca. He is responsible of the "Technology Strategy" area at the M.B.A. Program of Politecnico di Milano. He obtained his Master Degree in Electronic Engineering cum laude at Politecnico di Milano. He was previously with Ciba-Geigy and Pirelli, Senior Researcher at the National Research Council of Italy (Istituto di Tecnologie Industriali e Automazione, Milano), Associate Professor at University of Castellanza, Full Professor at University of Milano-Bicocca. He was Visiting Researcher at London Business School and Guest Professor of Innovation Management at the University of Nijmegen (The Netherlands). He is member of the Board of the Italian Association of Engineering Management. His main research areas concern: R\&D management and organisation, technology strategy, international R\&D; creation of start-up and spin-off companies; technology transfer. He is author of the books 'R\&D Strategy and Organisation', Imperial College Press, 2001; 'La bioindustria', Etas, 2003. He is author of more than 100 papers on international journals, books, conference proceedings. 
Davide Chiaroni is a PhD student at Politecnico di Milano, Department of Management Engineering. He achieved his Master Degree in Management Engineering at Politecnico di Milano cum laude in 2002. He was previously a Research Assistant at University of Milano-Bicocca, Department of Biotechnology and Biosciences. His research area is strategy and strategic management in high-tech industries. 


\section{Contents}

Preface $\quad$ V

Contributors ix

Authors $\quad$ xi

1. The Concept of Cluster and the Cleverbio Project 1

1.1 The Concept of Cluster . . . . . . . . . . . . . . . . . . . 1

1.2 The Advantages from Clustering . . . . . . . . . . . 3

1.3 The Cleverbio Project: An Overview . . . . . . . . . . 6

Appendix ....................... 9

2. The Biotech Industry: An Overview 17

2.1 Introduction . . . . . . . . . . . . . . 17

2.2 The Bio-Pharmaceutical Value Chain . . . . . . . . . . . 19

2.2.1 The Value Chain . . . . . . . . . . . . . . . . . . . 19

2.2.2 Time, Risk and Cost of the Drug Discovery and

Development Process . . . . . . . . . . . . . . 24

2.3 The Structure of the Bio-Pharmaceutical Industry . . . . . 26

2.3.1 Biotech Companies: A Taxonomy . . . . . . . . 27

2.3.2 Main Figures in the Bio-Pharmaceutical Industry . 28

2.4 The Industry Structure: A Geographical Analysis . . . . . 45 
3. The Cluster of Cambridge

(by Jeff Solomon and Claire Skentelbery)

3.1 History of the Cluster . . . . . . . . . . . . . . . . 49

3.2 Major Actors . . . . . . . . . . . . . . . 51

3.2.1 Dedicated Biotech Firms . . . . . . . . . . 51

3.2.2 Industrial and Research Environment . . . . . . . 57

3.2.3 Financial Environment . . . . . . . . . . . . 61

3.3 Context Factors . . . . . . . . . . . . . . . . 63

3.4 Conclusions .................... 66

4. The Cluster of Heidelberg 71

(by Klaus Plate and Marion Kronabel)

4.1 History of the Cluster . . . . . . . . . . . 71

4.2 Major Actors . . . . . . . . . . . . . . . . 75

4.2.1 Dedicated Biotech Firms . . . . . . . . . . 75

4.2.2 Industrial and Research Environment . . . . . . . . 82

4.2.3 Financial Environment . . . . . . . . . . . . . . . 84

4.3 Context Factors . . . . . . . . . . . . . . . . . . . . . . . 84

4.4 Conclusions .................... 87

5. The Cluster of Aarhus 91

(by Gyda Marie Bay and Jørn Enggaard)

5.1 History of the Cluster . . . . . . . . . . . . . 91

5.2 Major Actors . . . . . . . . . . . . . . . . . . . 93

5.2.1 Dedicated Biotech Firms _. . . . . . . . . . 93

5.2.2 Industrial and Research Environment . . . . . . . . 99

5.2.3 Financial Environment . . . . . . . . . . . 101

5.3 Context Factors . . . . . . . . . . . . . . . . . . . 102

5.4 Conclusions .................... 103

6. The Cluster of Marseilles 107

(by Jean Laporta and Françoise Perrin)

6.1 History of the Cluster . . . . . . . . . . . . . 107 
6.2 Major Actors . . . . . . . . . . . . . . . . . . 110

6.2.1 Dedicated Biotech Firms . . . . . . . . . . . 110

6.2.2 Industrial and Research Environment . . . . . . . . 119

6.2.3 Financial Environment . . . . . . . . . . . 121

6.3 Context Factors . . . . . . . . . . . . . . . . . . 121

6.4 Conclusions . . . . . . . . . . . . . . . 123

$\begin{array}{ll}\text { 7. The Cluster of Milan } & 127\end{array}$

7.1 History of the Cluster . . . . . . . . . . . . . . . . 127

7.2 Major Actors . . . . . . . . . . . . . . . . . . . . . . . 129

7.2.1 Dedicated Biotech Firms . . . . . . . . . . . . . . 129

7.2.2 Industrial and Research Environment . . . . . . . . 140

7.2.3 Financial Environment . . . . . . . . . . . . 141

7.3 Context Factors . . . . . . . . . . . . . . . . . 142

7.4 Conclusions ................... 145

8. Other Cases of Biotech Clusters 149

8.1 The Cluster of San Diego . . . . . . . . . . . . . . . . . . . . . . . . . . . . . . .

8.2 The Bay Area . . . . . . . . . . . . . . . . . . . . 154

8.3 The Cluster of Evry . . . . . . . . . . . . . . . . 157

8.4 The Cluster of Munich . . . . . . . . . . . . . . . . . . 159

8.5 The Cluster of Oxford . . . . . . . . . . . . . . . 160

8.6 The Biovalley . . . . . . . . . . . . . 163

8.7 The Cluster of Uppsala . . . . . . . . . . . . . . 165

9. The Normative Model 167

9.1 Growth Mechanisms of a Cluster . . . . . . . . . . . . 167

9.2 Driving Forces and Practices . . . . . . . . . . . . . . . 169

9.2.1 Financial Driving Forces . . . . . . . . . . 170

9.2.2 Scientific Driving Forces . . . . . . . . . . . . . 181

9.2.3 Industrial Driving Forces . . . . . . . . . . . . 192

9.2.4 Supporting Driving Forces . . . . . . . . . . . 201

9.3 The Normative Model . . . . . . . . . . . . . . . . . . . . 212 
10. Conclusions: Forms of Cluster Creation in Biotech 213

10.1 Spontaneous Clusters . . . . . . . . . . . . . . . 214

10.2 Policy-Driven Clusters . . . . . . . . . . . . 215

10.2.1 Industry Restructuring Policies . . . . . . . . . 215

10.2.2 Industry Development Policies . . . . . . . . 216

10.3 Hybrid Clusters . . . . . . . . . . . . . . . . . . 217

References and Further Readings 